\title{
Recycling of Cathode Ray Tubes (CRTs) in Electronic Waste
}

\author{
Sunil Herat \\ Senior Lecturer, Griffith School of Engineering, Nathan Campus, Griffith University, \\ Queensland 4111, Australia. \\ Tel: +61 737356682 \\ E-mail address: s.herat@griffith.edu.au
}

Key Words: Cathode ray tube; Closed -loop recycling; Electronic waste; Glass; Open-loop recycling 


\begin{abstract}
The management of used electrical and electronic equipment (EEE) or e-waste is a significant problem worldwide due to rapid uptake of the technology and early obsolescence of EEE. Cathode ray tubes (CRTs) from used televisions and computer monitors represent a major e-waste problem as they consist of glass with different compositions. The front panel is a lead-free barium-strontium glass whereas parts such as the funnel hidden inside are composed of glass with lead oxides. Regulations require the glass from waste CRTs to be recycled or re-utilised. Closed-loop recycling and open-loop recycling are two principal ways of recycling the CRT glass. The aim of this paper is to examine the technical characteristics and composition of the CRTs, its generation, environmental impacts and related regulatory requirements and review the current technologies and their limitations for recycling CRT glass and its end use.
\end{abstract}

\title{
1 Introduction
}

The demand for consumer electrical and electronic equipment (EEE) has been on the increase since 1980s and countless number of EEEs, especially computers and televisions have been sold to consumers around the world. Rapid advances in technology and ready availability of newer designs at cheap prices have motivated these customers to discard old EEEs even before their useful life is over. This has resulted in mountains of old EEEs, referred to as electronic waste or e-waste, to be managed by the relevant authorities. Finding a sustainable, economically viable, technically feasible and socially acceptable strategy to deal with end-of-life (EOL) management of EEEs has been not easy due to their sheer numbers and the toxic materials contained in them. Concepts such as extended producer responsibility and design for environment are being introduced in many countries by the authorities to encourage the manufacturers to avoid or minimise some of the materials used in the manufacture of EEEs. However, there needs to be a strategy to deal with the current stockpile of e-waste (historical waste), and potential e-waste from currently used EEEs. In this regard EOL recycling/reuse of EEEs is seen as one of the strategies with high potential.

A cathode ray tube (CRT), which is an evacuated glass envelope containing an electron gun and a fluorescent screen, is a device used as video display components of televisions and computers. With number of televisions and computers reaching their EOL, the electronic industry is confronted with a major problem of dealing with the used CRTs. It is estimated that CRT glass accounts for approximately $47 \%$ by weight of commercial electronics and 30\% by weight of data processing equipment and also contains metals such as lead, strontium, antimony and barium [1]. Dismantling the CRTs in used EEE and removing the metal coatings in the CRT glass are major challenges faced by the electronics recycling industry.

The aim of this paper is to examine the technical characteristics and composition of the CRTs, its generation and environmental impacts, related regulatory requirements and review the current recycling initiatives to recover/reuse CRT glass and review developments and the markets for recovered CRT glass. 
There are two types of CRTs: black and white (monochrome) and colour. The monochrome CRT consists of a front panel used as the screen, a neck which envelopes the electron gun and funnel which connects the panel and the neck. The panel and the funnel are manufactured by pressing and sealing together. A colour CRT consists of a panel, a shadow mask, a glass funnel and an electronic gun. The shadow mask is the thin sheet metal located immediately behind the glass panel. The glass funnel in a shape of a funnel is attached to the back of the glass panel, both connected together using a glass frit solder. At the back end (neck), the glass funnel holds the electron gun which produces electrons that strike the glass panel and produce the images in televisions and monitors. It is estimated that CRT constitutes around $65 \%$ of the weight of a television or a computer monitor and is composed of $85 \%$ glass of which the front panel contributes $65 \%$, funnel $30 \%$ and neck glass $5 \%$ $[2,3]$.

The front panel of the CRT is made of very homogenous barium-strontium glass (up to $12 \%$ barium oxide and up to $12 \%$ strontium oxide) whose weight is about two thirds of the whole CRT while the funnel is a lead glass (up to $25 \%$ lead oxide) whose weight is around one third of the whole CRT. The neck of the CRT which envelopes the electron gun consists of a glass with very high lead content (up to $40 \%$ lead oxide) while the frit consists of a low melting lead glass (up to $85 \%$ lead) $[4,5]$. The amount of lead oxide present in CRTs varies from $0.5 \mathrm{~kg}$ for a 12 " CRT to $3 \mathrm{~kg}$ for a 32" CRT [4]. Apart from lead, barium and strontium oxides, the CRT glass also contain oxides of silicon, sodium, potassium, aluminium and calcium. These are also common in commercial glass applications. In addition, the inside of the CRT panel is coated with layers of phosphor which may also contain cadmium and other metals. The outer section of the funnel section is coated with graphite and inner section with iron oxide [6].

\section{$3 \quad$ Generation of Waste CRTs}

Waste CRTs are mainly generated from used televisions and computers. There are various estimates available for discarded televisions and computers around the world. In the United States, where it is believed to be the largest e-waste producer in the world, it is estimated that over 100 million computers, monitors and televisions become obsolete each year and that amount is growing each year [7]. Other estimates state that over 500 million computers will become obsolete in the United States between 1997 and 2007 [8]. The United States Environmental Protection Agency (US EPA) estimates that e-waste accounts for 1 to $4 \%$ of the municipal solid waste stream but is growing at three times the rate of other household waste [9]. Also in the United States it was estimated that around 500 million CRTs were stockpiled in households up to year 2003 [10]. It is estimated that in China 5 million new computers and 10 million new televisions are purchased every year since 2003 [11]. In the United Kingdom it is estimated that in 2002, 104,532 tonnes of CRT glass were generated out of which televisions contributed 69,000 tonnes and computer monitors contributed 26,000 tonnes [4]. Worldwide, it is estimated that 20 million computers became obsolete in 1994 and this figure was to increase to 100 million by the year 2004 [12]. 
Environmental impacts of waste CRTs arise mainly from its lead content. Lead is a naturally occurring metal in the earth's crust. Lead itself does not break down but the characteristics of lead compounds could change due to environmental conditions. For example, although under normal conditions lead does not react with water, when metallic lead comes in contact with moist air its reactivity with water increases and lead hydroxide may be formed. Once released into air lead could stay in the atmosphere for a long time prior to falling and sticking onto soil with a possible leaching into groundwater. Lead can affect almost every organ in the body including the nervous system, kidneys and reproductive system. The main effect of lead toxicity is on the central nervous system of the humans. High exposure of lead could also severely damage the brain and kidneys of the humans and could lead to miscarriage in pregnant women. High levels of lead could also affect the brain development of children and organs responsible for sperm production in men [13].

The main environmental effect of lead is the leaching of lead ions from broken lead containing glass (e.g. broken cone glass of CRTs) when mixed with acid waters in waste landfills. It is estimated that $40 \%$ of lead found in United States landfills comes from EEE [12]. A study by Turbini et al [14] reports of a US EPA commissioned study of municipal solid waste (MSW) to determine whether the leaching of lead from landfills presents a problem. This study found that $40.2 \%$ of lead in MSW comes from consumer electronic devices of which television picture accounts for $35.8 \%$ with the remaining $4.4 \%$ from other sources. Hence lead from CRTs could pose a major risk to the environment.

\section{$5 \quad$ Regulatory Requirements}

To minimise the environmental impact of waste CRTs number of regulations have been developed around the world. The forefront of these is the Waste Electrical and Electronic Equipment (WEEE) Directive requiring the recovery and recycling of many EEEs and became law in February 2003. It applies to all the Member States of the European Union and makes the producers responsible for financing the collection, treatment, and recovery of WEEE and requires the distributors of WEEE to allow the consumers to return their waste equipment free of charge. The directive was agreed by European Parliament on 13 February 2003, transposed into Member State legislation on 13 August 2004 and came into force on 13 August 2005 [15]. The WEEE directive covers number of categories of EEEs of which CRTs are contained in two types of categories; Category 3 - IT and Telecommunication equipment which covers computer monitors and Category 4 - Consumer Equipment which covers televisions. The main components of the Directive are as follows:

- Effective from 13 August 2005, WEEE must be collected separately from unsorted municipal waste. To achieve this producers are required to set up convenient public collection points so that private households are able to return their WEEE free of charge. The directive also requires that by 31 December 2006, above collection points must achieve a collection rate of at least $4 \mathrm{~kg}$ of WEEE per person per year.

- The directive makes the producers responsible for the costs of collection, treatment, recovery and disposal of their own products. The producers are also 
required to cover the above costs for products put on market prior to 13 August 2005 in proportion to their current market share by type of equipment.

Recovery and recycling rates to be achieved by 31 December 2006 for different types of equipment are defined in the Directive. For equipment containing CRTs the recycling target is $65 \%$ and the recovery target is $75 \%$ [15].

The European Union also passed another Directive on the Restriction of the Use of Certain Hazardous Substances in EEE (RoHS) which requires the Member States to phase out the use of hazardous substances lead, mercury, cadmium, hexavalent chromium, polybrominated biphenyls (PBB) and polybrominated diphenyl ethers (PBDE)[16]. The RoHS directive came into effect on 1 July 2006 and applies to new electrical and electronic equipment put on the European market on or after July $1^{\text {st }}$. The maximum tolerated value for lead, mercury, hexavalent chromium, PBB and PBDE is $0.1 \%$ by weight in homogenous materials and $0.01 \%$ by weight in homogenous materials for cadmium [17].

In Japan an amendment to the Law for the Effective Utilisation of Resources took place on 1 July 2006 when the Japanese version of the RoHS (also known as J-Moss or JIS C 0950) was introduced. Manufacturers and importers are required to label their products and provide information on the six EU RoHS substances: lead, mercury, chromium VI, cadmium, PBB and PBDE. In China, Measures for the Administration of the Control of Pollution by Electronic Information Products, Directive was promulgated by the Ministry of Information Industry and other participating agencies on 28 February 2006 and came into effect on 1 March 2007. The goal is to make companies disclose and control the use of hazardous/toxic materials through disclosure via labelling requirements and control via substance restrictions. The substances covered by this law are the same six substances covered by EU RoHS. On 2 April 2007, Korea's National Assembly passed the 'Act Concerning the Resource Recycling of Electrical/Electronic Products and Automobiles' which has similarities to EU's RoHS, WEEE and ELV (End of Life Vehicles) Directives but also containing items specific to Korea. Also known as Korea's RoHS this regulation goes into force on January 1, 2008.

In the United States many CRTs are currently classified as hazardous wastes under the Resource Conservation and Recovery Act (RCRA). They are therefore subjected to the hazardous waste regulations of RCRA Subtitle $C$ unless they come from a household or a conditionally exempt small quantity generator. On 28 July 2006, US EPA finalised a conditional exclusion of CRTs and glass removed from CRTs that are recycled from the RCRA definition of solid waste to encourage recycling of CRTs. According to this rule which came to effect on 29 January 2007, CRTs and CRT glass that qualify for the exclusion are not considered hazardous.

Also, as of April 2007, at least seven States in the United States (Arkansas, California, Maine, Massachusetts, Minnesota, New Hampshire and Rhode Island) have banned the landfill disposal of various types of electronic waste including the CRTs and four States (California, Maine, Maryland and Washington) have passed comprehensive recycling legislation. Furthermore, at least 16 States and New York City have proposed recycling legislation in 2007 to adopt either an advanced recovery fee or an extended producer responsibility scheme [18]. 
When recycling waste CRTs, recovered glass can be used in further manufacture of CRTs (closed-loop recycling) or into other products (open-loop recycling). Recycling of waste CRTs consists of two broad technologies: Glass-to-Glass and Glass-to-Lead recycling.

Glass-to-Glass recycling is a closed-loop process where waste CRTs are sent to CRT manufacturers to obtain the leaded and unleaded glass required for manufacturing new CRTs. The process involves following steps [19]:

- Removing the CRT from plastic casing;

- Releasing the vacuum in the tube;

- Removing various metals and non-glass metals including the electron gun;

- Separating panel glass from funnel glass; and

- Removing the phosphor coatings from the panel glass

Although glass-to-glass recycling of CRT glass enables replacement of the virgin materials with recycled cullet at equal or lower cost and improve the quality of output glass as a result of using high quality recycled glass, the difficulty of identifying glass composition (different manufacturers use different compositions), high cost of collection and significant labour involvement form barriers to the process [20].

Glass-to-lead recycling involves separating and recovering metallic lead and copper from waste CRT glass using a smelting process. Recovered CRT glass goes into the lead smelter and acts as fluxing agent in the smelting process. The process is automated compared to glass-to-glass recycling hence more cost effective. The process also safeguards workers from inhaling lead dust [21].

\subsection{Barriers to recycling waste CRTs}

CRT manufacturing process is a complicated and sensitive process hence exact knowledge of raw materials is needed to avoid any production shut downs due to contamination. Although the CRT manufacturers are well aware of the raw materials used in traditional CRT glass manufacturing, this is not the case with using recycled CRT glass. For this reason some CRT manufacturers are reluctant to use scrap CRT glass. Hence not knowing the exact composition of the recycled glass is one of the main barriers to recycling. In addition there are further barriers for recycling waste CRT glass as described below [2, 22]:

- Open-loop recycling is difficult process (compared to closed-loop) as it is difficult to use waste CRT glass which may contain elements such as lead and cadmium in products such as glass containers, table-ware or glass fibres. The presence of barium and strontium are not welcomed by glass fibre manufacturers even with encouraging experimental evidence;

- The inner surface of the panel glass is coated with different layers which consist of different types of heavy metals and hazardous substances. For example, the 
fluorescent powder coating used in colour CRTs contain cadmium and phosphorus. These materials hinder the recycling of CRT glass;

- The recycling technologies for ordinary bottle glass is readily available compared to recycling technology for CRT glass and collection infrastructure for ordinary glass is well established worldwide. This has resulted in a surplus supply of recycled glass for ordinary glass manufacturing industry;

- The recycling infrastructure for scarp televisions and computer monitors is not well established in many countries resulting in low generation of scarp CRT glass.

\subsection{Separating panel glass from the funnel}

As noted above it is very important to separate the panel glass (non-leaded glass) of a CRT from funnel glass (leaded glass) to avoid contamination and improve the efficiency of recycling. Various methods are available to separate the panel glass from funnel glass as described below [4, 23, 24]:

\subsubsection{Electric wire heating method}

Electric wire heating method uses a special electrical wire (e.g. NiChrome wire) wound around the interface between the panel and the funnel glass. An electric current is passed through the wire to heat the wire for a designated period and then cooled using cool air. As a result of the thermal shock, the CRT breaks along the interface separating the two glasses. The potential problems associated with this method includes the formation of sharp edges on separated fractions, difficulty in getting a clean separation if the wire is incorrectly placed and the glass not always breaking along the wire line. This method is more appropriate for processing small to medium quantities of CRT glass, and requiring low investment capital.

\subsubsection{Gravitational-fall method}

In this method the CRT is lifted to a designated elevation and allowed to drop while the funnel glass is facing downwards. The panel glass can be manually separated from the funnel glass when the funnel glass breaks on the impact with a surface. Although this is a simple and low cost procedure a clearer separation may be difficult to achieve.

\subsubsection{Thermal shock and laser cutting methods}

In this method CRT is subjected to localised heat and followed by cold air to induce a thermal stress at the frit line where the funnel glass and panel glass are joined. The laser method is similar to the above where the thermal shock is created by a laser beam which is focussed inside the CRT and followed by a cold water spray. The problems associated with this process include reformation of the glass after the laser beam has passed through and the difficulty of cutting thick glass. The laser process is energy intensive and requires significant investment capital. However the process can be utilised for large scale operations. 


\subsubsection{Diamond saw method}

This process can be undertaken under wet or dry conditions. Wet saw method involves rotating the CRT in an enclosure while diamond saw blades cut through the CRT around the interface of the two glasses. Coolant water is sprayed to CRT during the process. In this process a clean separation can be achieved provided the CRT is correctly aligned with the saw blades and can be used for large scale operations although it requires high capital investments.

\subsubsection{Water jet separation}

This method uses a high-pressure spray of water containing abrasive materials and directed at the surface where the separation is needed.

\subsection{Removal of coatings from panel glass}

The following four coatings are applied to inner surface of the panel glass in a CRT [22]:

- Mixture of carbon slurry and other surfactants as the first layer to produce carbon black and clear stripes on the interior;

- Three fluorescent colours (green, blue and red) are filled into clear areas as the second coating;

- Lacquer is applied on the surface of the second coating to smooth and seal the inner surface of the glass panel;

- Fourth coating layer is an aluminium film applied to the inner surface to enhance brightness.

The coating of fluorescent colours contains several metals which are of concern hence needed to be removed prior to recycling. There are various technologies for the removal of the coatings which include technologies such as the vacuum suction method (a vacuum-suction device is used to suck loose coatings from the panel glass surface), ultrasonic-cleaning method (broken CRT glass is immersed into a cleaning fluid containing water and acid and placed in an ultrasonic device for a period of time), wet-scrubbing method (broken CRT glass is placed in a tumbling mill with water and coatings scrubbed off ) and sandblasting method (small steel balls are blasted onto glass surface by a high-pressure air jet) [22, 23]:

\section{$7 \quad$ End Uses of Recovered CRT Glass}

The two major industries that have potential to use recovered CRT glass (open-loop recycling) are glass industry and the ceramic industry. Some examples of end use of CRT glass in these industries and other industries are described in this section. 


\subsection{Foam glass}

Foam glass or cellular glass is mainly used for thermal and sound insulation purposes and for ground stabilisation. Foam glass is manufactured by generating a gas in glass at a temperature between $700^{\circ} \mathrm{C}$ and $900^{\circ} \mathrm{C}$. As a result the gas expands producing a structure of cells within the glass to form a porous body. The present day foam glass industries are using up to $98 \%$ post consumer waste glass in their products [4].

Foam glass could also be made by foaming gases resulting from chemical reactions simultaneous to sintering (a process for making objects from small particles by heating the material below its melting point until its particles adhere to each other) without the need for introducing gases within molten glass. In this process foaming is achieved by an oxidation process using carbon based foaming agents such as graphite, coal, carbon black or pyrolytic residues in fly ashes and carbide (SiC) or by a decomposition process using carbonates (e.g. carbonates of sodium, calcium, magnesium) or sulphites (e.g. gypsum). The main advantage of the decomposition process is that it's suitable for waste glasses containing heavy metals as oxidation reactions with carbonaceous substances are avoided [25].

The feasibility of using recycled CRT glass in foam glass manufacture has been investigated by several researches. Mear et al [1] studied the characterisation of foam glass produced from CRT glass powder and reducing agents titanium nitride (TiN) and silicon carbide (SiC). They measured the parameters such as density, porosity, thermal and mechanical properties and found that reutilisation of CRT glass in the form of foam glass is a recycling process with high potential. Several other studies have investigated the effects of parameters such as reaction time, temperature and mass percentage of reducing agent on the reaction process and the physical and chemical properties of foam glass produced from CRT glass to determine the optimum conditions [26-29].

\subsection{Ceramic products}

It is difficult to use funnel glass in many open-recycling systems due to its lead content. In glass products such as container glass and tableware, raw materials with high lead content are not allowed. However, in the ceramic industry, it is possible to use both panel and funnel glass from CRTs as the restrictions are much lower. A case study by Andreola et al [2, 30] investigated the use CRT glass (panel and funnel) as secondary raw material substitutes for common 'ceramic frits' used in the manufacture of commercial glazes. The investigation undertaken in the laboratory as well as in the industry found that glazes obtained from using CRT glass have similar aesthetic and mechanical properties to standard glazes. The investigators also conducted a life cycle assessment (LCA) on the standard glaze and CRT glass glaze. The results showed that the production of glaze with CRT glass leads to an overall reduction of environmental damage by $36 \%$ compared to standard glaze production.

Andreola et al [31] also investigated the potential of using CRT glass in glassceramics manufacture. Glass-ceramics have properties of both glass and traditional crystalline ceramics and are used very commonly in cook tops. The results obtained indicate that CRT glass is very versatile for this purpose because if they are mixed 
with suitable raw materials such as dolomite or alumina and subjected to adequate thermal treatments they can be used in glass-ceramic manufacture.

\section{Concluding Remarks}

Generation of waste from EEEs is increasing at a rapid rate worldwide surpassing the rate of generation of normal municipal waste. Used televisions and computer monitors form a significant portion of this waste stream. CRT is the largest component of both of these devices. Replacement of standard-definition television with high-definition television (without CRT) and the increasing popularity of LCD monitors (without CRT) in computers will have a major impact on the generation of waste CRTs. Recycling CRT glass is not easy because it is composed of four different types of glasses - panel, funnel, neck and frit- with varying material compositions. Closedloop recycling and open-loop recycling are two principal ways of recycling the CRT glass. For closed-loop recycling varying material composition of CRT glass among different manufacturers, high labour cost of dismantling the CRT, cheap and ready availability of other recycled glass and high collection costs form major barriers to overcome. Furthermore it is expected that demand for CRTs will diminish in the coming years as a result of the move to LCD or plasma systems. This will have a major impact on closed-loop recycling and the recycling market may have to rely heavily upon open-loop recycling such as lead smelting.

Given the above mentioned limitations of closed-loop recycling, the next best strategy for CRT recycling may be the open-loop recycling even with the presence of elements such as lead and other heavy metals which forbids their use in many applications. As the availability of opportunities for closed-loop recycling declines in the coming years there is a definite need to invest in research and development for open-loop recycling to make it more environmentally friendly than now. The use of recycled CRT glass in the glass and ceramic industry is becoming popular although much of the progress is in the research state with good experimental results. The challenge for the future is how to transfer these results into practice given the preference to economic aspects over environmental aspects in many situations. For both closed-recycling and openrecycling to prosper under these conditions one of the most important parameters is the quality of end of life CRT glass. Through drives such as legislation and practices such as cleaner production and design for environment it is hoped that high quality CRT glass is made available for efficient and economical reuse and recycling.

\section{References}

[1] F. Mear, P. Yot, M. Cambon, A.M. Ribes, Elaboration and characterisation of foam glass from cathode ray tubes, Adv. Appl. Ceram. 2005, 104, 123-130.

[2] F. Andreola, L. Barbieri, A. Corradi, I. Lancellotti, CRT glass state of the art A case study: Recycling in ceramic glazes, J. Eur. Ceram. Soc. 2007, 27, 1623-1629.

[3] United States Environmental Protection Agency, General Background Document on Cathode Ray Tube Glass to Glass Recycling, Report prepared by ICF Incorporated, Fairfax, Virginia, USA 1999, p. 26.

[4] Industry Council for Electronics Equipment Recycling, Material Recovery from Waste Cathode Ray Tubes (CRTs), Report published by Waste and Resources Action Programme, UK 2004, p. 70. 
[5] F. Mear, P. Yot, M. Cambon, M. Ribes, The characterization of waste cathode-ray tube glass, Waste Manag. 2006, 26, 1468-1476.

[6] Industry Council for Electronics Equipment Recycling, New Approach to Cathode Ray Tube (CRT) Recycling, Department of Trade and Industry, UK, 2003, p. 34.

[7] United States Government Accountability Office, Electronic Waste: Strengthening the Role of the Federal Government in Encouraging Recycling and Reuse, Report GAO-06-47, USA 2005, p. 57.

[8] P. Huang, X. Zhang, X. Deng, Survey and analysis of public environmental awareness and performance in Ningbo, China: a case study on household electrical and electronic equipment, J. Clean. Prod. 2006, 14, 1635-1643.

[9] B. Hileman, Electronic waste, Chem. Eng. News. 2006, 84, 18-21.

[10] D. Kim, I.G. Petrisor, T.F. Yen, Evaluation of biopolymer-modified concrete systems for disposal of cathode ray tube glass, J. Air Waste Manage. Assoc. 2005, 55, 961-969.

[11] C. Hicks, R. Dietmar, M. Eugster, The recycling and disposal of electrical and electronic waste in China - legislative and market responses, Environ. Impact. Assess. Rev. 2005, 25, 459-471.

[12] R. Widmer, H. Oswald-Krapf, D. Sinha-Khetriwal, M. Schnellmann, H. Boni, Global perspectives on e-waste, Environ. Impact. Assess. Rev. 2005, 25, 436458.

[13] ATSDR, Lead: Agency for Toxic Substances and Disease Registry Fact Sheet, United States Department of Health and Human Services, 2005, p. 2.

[14] L.J. Turbini, G.C. Munie, D. Bernier, J. Gamalski, D.W. Bergman, Examining the environmental impact of lead-free soldering alternatives, IEEE Transactions on Electronics Packaging Manufacturing 2001, 24, 4-9.

[15] European Union, Directive 2002/96/EC of the European Parliament and the Council of 27 January 2003 on waste electrical and electronic equipment (WEEE), Official J. Eur. Union. 2003, 46, 24-39.

[16] European Union, Directive 2002/95/EC of the European Parliament and of the Council of 27 January 2003 on the restriction of the use of certain hazardous substances in electrical and electronic equipment, Official J. Eur. Union. 2003, 46, 19-23.

[17] European Union, Commission Decision of 18 August 2005 amending Directive 2002/95/EC of the European Parliament and of the Council for the purpose of establishing the maximum concentration values for certain hazardous substances in electrical and electronic equipment, Official J. Eur. Union. 2005, 48, 65.

[18] J.S. Solmer, R.G. Stoll, United States: Electronic Waste - New Developments, Folley and Lardner, MA, USA 2007.

[19] D.H. Weitzman, Is CRT glass-to-lead recycling safe and environmentally friendly?, IEEE Int. Symp. Electronics and the Environment, USA 2003, 329334.

[20] H.-Y. Kang, J.M. Schoenung, Used consumer electronics: a comparative analysis of materials recycling technologies, IEEE Int. Symp. on Electronics and the Environment, USA 2004, 226-230.

[21] H.Y. Kang, J.M. Schoenung, Electronic waste recycling: A review of US infrastructure and technology options, Resou.r Conserva.t Recycl. 2005, 45, 368-400. 
[22] C.H. Lee, C.S. Hsi, Recycling of scrap cathode ray tubes, Environ. Sci. Tech. 2002, 36, 69-75.

[23] C.H. Lee, C.T. Chang, K.S. Fan, T.C. Chang, An overview of recycling and treatment of scrap computers, J. Haz. Mater. 2004, 114, 93-100.

[24] E.S. Geskin, B. Goldenberg, R. Caudill, Development of advanced CRT disassembly technology, IEEE Int. Symp. on Electronics and the Environment, USA 2002, 249-253.

[25] E. Bernardo, F. Albertini, Glass foams from dismantled cathode ray tubes, Ceram. Int. 2006, 32, 603-608.

[26] F. Mear, P. Yot, M. Ribes, Effects of temperature, reaction time and reducing agent content on the synthesis of macroporous foam glasses from waste funnel glasses, Mater. Lett. 2006, 60, 929-934.

[27] F. Mear, P. Yot, M. Cambon, R. Caplain, M. Ribes, Characterisation of porous glasses prepared from Cathode Ray Tube (CRT), Powder Technol. 2006, 162, 59-63.

[28] F. Mear, P. Yot, R. Viennois, M. Ribes, Mechanical behaviour and thermal and electrical properties of foam glass, Ceram. Int. 2007, 33, 543-550.

[29] F. Mear, P. Yot, M. Cambon, M. Ribes, The changes in lead silicate glasses induced by the addition of a reducing agent (TiN or SiC), J. Non-Crystal. Solids 2005, 351, 3314-3319.

[30] F. Andreola, L. Barbieri, A. Corradi, I. Lancellotti, Cathode ray tube glass recycling: an example of clean technology, Waste. Manag. Res. 2005, 23, 314321.

[31] F. Andreola, L. Barbieri, A. Corradi, I. Lancellotti, R. Falcone, S. Hreglich, Glass-ceramics obtained by the recycling of end of life cathode ray tubes glasses, Waste Manage. 2005, 25, 183-189. 